\title{
PENINGKATAN KEMAMPUAN PENALARAN MATEMATIS DAN SELF ESTEEM SISWA KELAS V MELALUI STRATEGI MULTIPLE INTELLIGENCES \\ Oleh:
}

Fauzan $^{1}$, Tatang Herman ${ }^{2}$

Universitas Pendidikan Indonesia

\begin{abstract}
This study focused on looking at the extent to which differences in mathematical reasoning capacity building and self-esteem of students who take the multiple intelligences learning strategy and regular learning. The research subject is a fifth grade students from two different classes at the same school. There are two main instruments used to collect data that achievement test and attitude scale. Both classes are given the same instrument. The results showed that there are significant differences between the mathematical reasoning abilities of students who take the multiple intelligences learning strategy and regular learning. In contrast, there are no significant differences between self-esteem of students who take the multiple intelligences learning strategy and regular learning. The study's findings provide awareness that the teacher has a very important role in facilitating student learning. Although directed to student centered learning, but nonetheless pedagogical, especially, must be owned by a teacher. Each person may be a teacher, but not everyone can be an educator. However, students will not reach the level of proficiency is high if not under the guidance of teachers who excel.
\end{abstract}

Keywords: mathematical reasoning, self-esteem, multiple intelligences

Abstrak: Penelitian ini fokus pada melihat sejauh mana perbedaan peningkatan kemampuan penalaran matematis dan self esteem siswa yang mengikuti pembelajaran dengan strategi multiple intelligences dan pembelajaran biasa. Subjek penelitian merupakan siswa kelas $\mathrm{V}$ yang berasal dari dua kelas yang berbeda pada satu sekolah yang sama. Terdapat dua instrumen utama yang digunakan untuk mengumpulkan data yakni tes hasil belajar dan skala sikap. Kedua kelas diberikan instrumen yang sama. Hasil penelitian menunjukkan bahwa terdapat perbedaan yang signifikan antara kemampuan penalaran matematis siswa yang mengikuti pembelajaran dengan strategi multiple intelligences dan pembelajaran biasa. Sebaliknya, tidak terdapat perbedaan yang signifikan antara self esteem siswa yang mengikuti pembelajaran dengan strategi multiple intelligences dan pembelajaran biasa. Temuan penelitian memberikan kesadaran bahwa guru memiliki peranan sangat penting dalam memfasilitasi siswa belajar. Meskipun pembelajaran diarahkan kepada student centered, tetapi tetap saja kompetensi pedagogik, terutama, mesti dimiliki guru. Setiap orang mungkin bisa menjadi guru, tapi tidak setiap orang bisa menjadi pendidik. Bagaimanapun, siswa tidak akan mencapai tingkat kemampuan yang tinggi jika tidak di bawah bimbingan guru yang unggul.

Kata Kunci: penalaran matematis, self esteem, multiple intelligences

\section{PENDAHULUAN}

Guru mesti memahami karakteristik kecerdasan yang dimiliki masing-masing siswanya. Dia harus senantiasa menyadari

betapa siswa memiliki keragaman dalam cara belajar. Beragam potensi yang satu sama lain berbeda. Tidak bisa

\footnotetext{
${ }^{1}$ Universitas Pendidikan Indonesia, Email: zan2505@gmail.com

${ }^{2}$ Dosen Universitas Pendidikan Indonesia, Email: tatangherman@upi.edu
} 
disamaratakan dalam pembelajarannya. Tai, F. M. (2014, hlm.19) mengemukakan bahwa untuk membantu keberagaman cara belajar siswa, guru yang efektif harus berusaha untuk memahami dan mengenali kecerdasan siswa. Untuk menyaring bakat siswa, membantu siswa menggunakan kombinasi kecerdasan mereka, dan menyiapkan lingkungan belajar yang sesuai harus benarbenar tidak boleh diabaikan.

Dari sekian banyak mata pelajaran yang diajarkan di setiap jenjang pendidikan, matematika hadir untuk mengembangkan potensi akal pikiran manusia. Dalam matematika, akal dan pikiran tampak begitu nyata peranannya. Matematika sangat memperhatikan prosedur dengan pola nalar yang kuat dalam penyelesaian masalahnya. Kesadaran terhadap matematika dihadirkan Allah bahkan semenjak manusia masih bayi, selain tentunya kemampuan berbahasa.

Eksperimen di University of Pennsylvania pada tahun 1980 (Eberle, 2011, hlm. 31) membuktikan bahwa bayi berusia enam belas minggu memperlihatkan respon terhadap perubahan jumlah objek, yaitu mereka dapat membeda-bedakan angka. Mereka menganggap bahwa memahami angka jauh sebelum mereka bisa menghitung. Kecerdasan matematika yang mendasar ini sebanding dengan bakat untuk prosodi (ilmu persajakan) yang terletak pada akar bahasa.

Dalam matematika, kemampuan penalaran memainkan peranan penting dalam pengembangan dan penerapannya. Terdapat dua macam penalaran, induktif dan deduktif. Penalaran induktif melibatkan persepsi tentang keteraturan. Misalnya, untuk mendapatkan kesamaan dari contohcontoh yang berbeda. Mendapatkan kesamaan tersebut dapat menjadi dasar dalam rangka pembentukan konsep, yaitu dengan cara mengurangi hal-hal yang harus diingat. Proses tersebut dinamakan abstraksi konsep. Sementara dalam penalaran deduktif, hubungan antara fakta dapat diturunkan menjadi konsep baru atau fakta baru bagi penurunan konsep-konsep yang lain. Proses menurunkan tersebut hingga didapat fakta baru atau konsep seringkali dapat dilakukan dengan mengandalkan kekuatan bernalar.

Melalui kegiatan bernalar, diharapkan siswa dapat melihat bahwa matematika merupakan kajian yang masuk akal atau logis. Dengan demikian siswa merasa yakin bahwa matematika dapat dipahami, dipikirkan, dibuktikan, dan dievaluasi.

Namun begitu, dalam pembelajaran di kelas, sebagaimana dikemukakan Muharom (2014, hlm. 3) bahwa, guru seringkali menjadi orang yang lebih aktif dalam proses pembelajaran dibandingkan dengan siswa. Hal itu mengakibatkan siswa menjadi pasif dan merasa jenuh dalam proses belajar. Sikap siswa pun menjadi takut dengan matematika. Kejenuhan tersebut dapat dilihat dari penerimaan materi. Mereka cenderung diam dan tidak berani mengeluarkan pendapat. Hal tersebut terjadi karena monotonnya pembelajaran yang dilaksanakan sehingga pikiran siswa tidak tereksplor dengan maksimal. Akibatnya kemampuan penalaran matematis siswa tidak berkembang dengan baik.

Salah satu penyebab rendahnya kualitas pemahaman siswa dalam matematika menurut hasil survey IMSTEPJICA (dalam Herman, 2006, hlm. 1) adalah dalam pembelajaran matematika guru terlalu berkonsentrasi pada hal-hal yang prosedural dan mekanistik seperti pembelajaran berpusat pada guru, konsep matematika sering disampaikan secara informatif, dan siswa dilatih menyelesaikan banyak soal tanpa pemahaman yang mendalam. Akibatnya, kemampuan penalaran dan kompetensi strategis siswa tidak berkembang sebagaimana mestinya. Bukti ini diperkuat lagi oleh hasil yang diperoleh The Third International Mathematics and Science Study (TIMSS) bahwa siswa SLTP Indonesia sangat lemah dalam problem solving namun cukup baik dalam keterampilan prosedural (Mullis, 
Martin, Gonzales, Gregory, Garden,

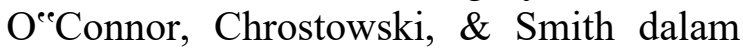
Herman, 2006, hlm. 1).

Selain itu, siswa juga perlu memiliki rasa pantas, layak, berharga, mampu dan berguna bagi sesamanya. Perasaan demikian diistilahkan self-esteem. Rusli Lutan (2003, hlm. 3) memaparkan bahwa "self-esteem adalah penerimaan diri sendiri, oleh diri sendiri berkaitan bahwa kita pantas, berharga, mampu dan berguna tak peduli dengan apapun yang sudah, sedang atau bakal terjadi. Tumbuhnya perasaan aku bisa dan aku berharga merupakan inti dari pengertian self-esteem".

\section{TINJAUAN PUSTAKA}

Teori multiple intelligences dikembangkan oleh Howard Gardner, seorang psikolog yang menitikberatkan pada pentingnya perbedaan individual. Dia memberikan pencerahan bahwa kita beranjak dari pemikiran "Secerdas apa Anda?" ke "Bagaimana Anda cerdas?". Ini merupakan hasil perkembangan kecerdasan majemuk (Gardner dalam DePorter, Reardon, dan Nourie, 2014, hlm. 137).

Terdapat tujuh tipe kecerdasan yang dimiliki oleh setiap orang menurut Gardner (2013, hlm. 39). Meskipun sebenarnya dia sendiri mengisyaratkan mungkin ada lebih banyak lagi kecerdasan. Ketujuh kecerdasan yang diidentifikasikan Gardner antara lain kecerdasan linguistik (berkaitan dengan bahasa), kecerdasan logis-matematis (berkaitan dengan nalar logika dan matematika), kecerdasan spasial (berkaitan dengan ruang dan gambar), kecerdasan musikal (berkaitan dengan musik, irama, dan bunyi/suara), kecerdasan badanikinestetis (berkaitan dengan badan dan gerak tubuh), kecerdasan interpersonal (berkaitan dengan hubungan antarpribadi, sosial), dan kecerdasan intrapersonal (berkaitan dengan hal-hal yang sangat mempribadi).

Pada perkembangannya, teori yang melihat keragaman cerdas dalam diri manusia itu bisa juga diaplikasikan dalam pembelajaran di kelas. Seperti Putrawan, dkk. (2011, hlm. 7) yang melakukan Penelitian Tindakan Kelas (PTK) untuk melihat sejauh mana efektivitas Strategi multiple intelligen-ces dapat meningkatkan pembelajaran jenis pekerjaan dan penggunaan uang. Pening-katan keefektifan dapat dilihat dari mening-katnya kualitas (quality), ketepatan (appropriateness), insentif (insentive), dan waktu (time).

Tafti, et al. (2014, hlm. 124) mengemukakan, menujukan kecerdasan majemuk peserta didik merupakan salah satu pendekatan membedakan, sebagai kegiatan yang ditawarkan yang menarik bakat siswa dalam semua kecerdasan. Diversifikasi instruksi, dengan memasukkan kecerdasan majemuk, akan membantu siswa menemukan kekuatan mereka dan menempatkan fokus pada kemampuan bukan kekurangan. Pendekatan yang berorientasi kuat kepada pendidikan, dan menawarkan pilihan siswa, akan membantu kepentingan siswa untuk dieksplorasi dan untuk mengakomodasi kebutuhan belajar terbaik mereka.

Sejalan dengan pendapat Lunenberg \& Lunenberg (2014, hlm. 6), dengan pembelajaran yang mengandung strategi multiple intelligences di kelas, siswa diberikan kesempatan untuk belajar otentik berdasarkan kebutuhan, minat, dan bakat siswa. Kelas dengan multiple intelligences di dalamnya seolah dunia yang nyata bagi siswa. Sebagaimana pendapat Gardner yang mempercayai bahwa kecerdasan yang sebenarnya harus dilakukan melalui pemecahan masalah dan mampu berkreasi secara alamiah.

Di sisi lain, penalaran matematika merupakan satu dari lima kompetensi yang ditargetkan dalam kurikulum matematika. Penalaran itu sendiri didefinisikan Lithner (2003, hlm. 29) sebagai jalan berfikir yang diambil untuk mengolah pernyataan dan menghasilkan kesimpulan dalam menyelesaikan soal. Lebih jauh Lithner mengemukakan, penalaran merupakan sebarang jalan berfikir dalam mengerjakan 
soal, sehingga penalaran tidak harus didasarkan pada deduktif formal dan menandakan prosedur yang singkat dalam menemukan fakta atau bukti-bukti.

Kemampuan penalaran matematik ini penting dimiliki oleh siswa. Penelitian di Malaysia yang dilakukan oleh Tajudin \& Chinnappan (2016, hlm. 97) menunjukkan bahwa rendahnya capaian nilai siswa di Malaysia pada TIMSS dan PISA dapat dikaitkan dengan rendahnya keterampilan penalaran matematik. Studi yang dilakukan menunjukkan bahwa keterampilan penalaran penting setidaknya untuk kelompok siswa asor. Kajiannya juga menunjukkan bahwa perlu dukungan tambahan dalam penalaran untuk mengerek prestasi yang baik di TIMSS dan PISA. Lebih dari itu lebih banyak usaha yang harus diinvestasikan dan siswa perlu terus didorong dalam pengembangan keterampilan penalaran.

Adapun kemampuan penalaran matematis yang diharapkan muncul pada diri siswa dalam penelitian di antaranya adalah kemampuan menarik kesimpulan yang logis dari permasalahan-permasalahan yang disajikan guru. Kemudian memberikan penjelasan dengan menggunakan fakta sesuai dengan batas kemampuan yang dimiliki oleh siswa. Yang terakhir adalah kemampuan untuk memperkirakan solusi dari permasalahan-permasalahan yang disajikan.

Sementara itu, self esteem adalah penerimaan diri sendiri, oleh diri sendiri yang berkaitan dengan kita pantas, berharga, mampu dan berguna, tak peduli dengan apa yang sudah, sedang atau bakal terjadi. Tumbuhnya perasaan "aku bisa" dan "aku berharga" merupakan inti dari pengertian self esteem (Lutan, 2003, hlm. 3).

Srivastava \& Joshi (2014, hlm. 37) berpendapat self esteem merupakan kepuasan terhadap diri sendiri. Istilah self esteem berasal dari kata Yunani yang berarti "penghormatan untuk diri". Bagian diri dari diri berkaitan dengan nilai-nilai, keyakinan dan sikap yang kami miliki tentang diri kita sendiri. Penghargaan bagian dari harga diri menggambarkan nilai dan layak yang satu memberikan diri. Singkatnya, self esteem adalah penerimaan dari kita untuk siapa dan apa yang kita pada waktu tertentu dalam hidup kita.

Pembentukan self esteem dimulai sejak saat anak lahir, ketika anak berhadapan dengan dunia luar dan berinteraksi dengan orang-orang di lingkungan sekitarnya. Interaksi ini yang kemudian menimbulkan pengertian tentang kesadaran diri, identitas, dan pemahaman tentang diri. Dengan demikian akan terbentuk penilaian orang lain terhadap dirinya sebagai orang yang berarti, berharga, dan menerima keadaan diri apa adanya.

Studi menemukan bahwa self-esteem yang rendah berpotensi menimbulkan perilaku antisosial, gangguan makan, depresi, hingga bunuh diri Erol \& Orth (2011, hlm. 607). Dalam menumbuhkan self esteem yang tinggi pada diri siswa, pihak sekolah dalam hal ini guru bukan satusatunya yang bertanggung jawab. Orang tua di rumah maupun lingkungan sekitar tempat siswa itu tumbuh dan berkembang memiliki peran penting. Sesuai dengan pandangan Baccus, et al. (2004, hlm. 501) bahwa reaksi self esteem implisit berakar dalam asosiasi mendasar antara representasi diri dan harapan positif terhadap umpan balik sosial yang negatif.

Untuk itu, Ho (2003, hlm. 82) menyarankan agar orang tua menciptakan ruang dan waktu di rumah dan aktif dalam melihat kemajuan studi anak-anak mereka, mengawasi pekerjaan rumah anak-anak mereka, menyediakan lingkungan belajar yang ideal, memperluas pengalaman belajar anak-anak mereka dengan kegiatan budaya seperti berangkat ke museum, serta membahas program TV dengan anak-anak mereka. Orang tua perlu memahami bahwa keterlibatan mereka lebih penting daripada investasi yang mereka gelontorkan untuk menciptakan lingkungan belajar dan merawat anak-anak mereka. 


\section{METODOLOGI PENELITIAN}

Penelitian ini dilakukan untuk melihat hubungan sebab-akibat yakni untuk melihat pengaruh penerapan strategi multiple intelligences pada pembelajaran matematika dalam meningkatkan kemampuan penalaran matematis dan self esteem siswa kelas V. Berdasarkan karakteristiknya maka penelitian ini termasuk ke dalam penelitian kuasi eksperimen.

Populasi pada penelitian ini adalah seluruh siswa kelas V SD se-Kecamatan Pamulihan Kabupaten Sumedang. Sampel yang dipilih adalah dua kelas V di salah satu SD Neger Kecamatan Pamulihan Kabupaten Sumedang. Kelas ini dipilih dengan asumsi awal memiliki masalah yang cocok untuk dipecahkan melalui penelitian. Dan yang terakhir dilakukan pemilihan kembali untuk kelas eksperimen dan kelas kontrol.

Instrumen yang digunakan untuk mengumpulkan data pada penelitian ini di antaranya tes hasil belajar, skala sikap, catatan lapangan, dan pedoman observasi. Data kuantitatif yang berhasil dikumpulkan dianalisis menggunakan software Microsoft Excel 2010 dan SPSS 20 for Windows. Untuk kemudian ditarik kesimpulan sebagaimana hipotesis penelitian yang telah disampaikan pada bagian terdahulu.

\section{HASIL PENELITIAN}

\section{Penalaran Matematis}

Data pretes kemampuan penalaran matematis siswa menunjukkan nilai signifikansi lebih dari 0,05 yaitu 0,482 , sehingga $\mathrm{H}_{0}$ diterima. Artinya tidak terdapat perbedaan yang signifikan antara rata-rata hasil pretes penalaran matematis siswa kelas dengan strategi multiple intelligences dan kelas dengan pembelajaran biasa. Dengan kata lain, kemampuan penalaran matematis siswa dengan strategi multiple intelligences dan kelas dengan pembelajaran biasa memiliki kesetaraan.

Sebaliknya, nilai p-value statistik uji-t untuk data postes kemampuan penalaran matematis siswa kelas dengan strategi multiple intelligences dan siswa kelas dengan pembelajaran biasa yaitu 0,004 atau kurang dari $\alpha=0,005$. Maka terdapat perbedaan antara kemampuan penalaran matematis siswa kelas dengan strategi multiple intelligences dan siswa kelas dengan pembelajaran biasa. Dengan kata lain, postes penalaran matematis siswa kelas dengan strategi multiple intelligences lebih baik secara signifikan daripada hasil postes kemampuan penalaran matematis kelas pembelajaran biasa.

Sementara itu, dilihat dari peningkatannya dengan menganalisis data gain ternormalisasi menunjukkan bahwa nilai signifikansi uji Mann-Whitney adalah 0,001. Nilai kurang dari 0,05. Artinya bahwa gain penalaran matematis siswa kelas dengan strategi multiple intelligences lebih baik secara signifikan daripada gain kemampuan penalaran matematis kelas pembelajaran biasa. Dengan demikian, peningkatan kemampuan penalaran matematis siswa yang memperoleh pembelajaran dengan strategi multiple intelligences lebih baik secara signifikan daripada peningkatan kemampuan penalaran matematis kelas pembelajaran biasa. Artinya hipotesis penelitian yang pertama diterima.

\section{Self Esteem}

Selanjutnya dilakukan analisis yang sama terhadap data self esteem. Nilai signifikansi untuk data pretes self esteem siswa lebih dari 0,05 yaitu 0,300 , sehingga $\mathrm{H}_{0}$ diterima. Artinya tidak terdapat perbedaan yang signifikan antara rata-rata hasil pretes self esteem siswa kelas dengan strategi multiple intelligences dan kelas dengan pembelajaran biasa. Dengan kata lain, self esteem siswa dengan strategi multiple intelligences dan kelas dengan pembelajaran biasa memiliki kesetaraan.

Hal yang sama ditunjukkan nilai pvalue statistik uji-t untuk data postes self esteem siswa kelas dengan strategi multiple intelligences dan siswa kelas dengan pembelajaran biasa yaitu 0,013 atau lebih 
dari $\alpha=0,005$. Maka tidak terdapat perbedaan antara self esteem siswa kelas dengan strategi multiple intelligences dan siswa kelas dengan pembelajaran biasa. Dengan kata lain, postes self esteem siswa kelas dengan strategi multiple intelligences tidak lebih baik secara signifikan daripada hasil postes self esteem kelas pembelajaran biasa.

Sementara itu, nilai signifikansi uji Mann-Whitney adalah 0,428. Nilai tersebut lebih dari 0,05. Artinya bahwa tidak terdapat perbedaan yang signifikan antara gain ternormalisasi self esteem siswa kelas dengan strategi multiple intelligences dan kelas dengan pembelajaran biasa. Dengan demikian, peningkatan self esteem siswa yang memperoleh pembelajaran dengan strategi multiple intelligences tidak lebih baik secara signifikan daripada rank hasil postes self esteem kelas pembelajaran biasa. Artinya hipotesis penelitian yang kedua tidak diterima.

\section{PEMBAHASAN}

\section{Penalaran Matematis}

Peningkatan kemampuan penalaran matematis siswa yang memperoleh pembelajaran dengan strategi multiple intelligences lebih baik secara signifikan daripada rank peningkatan kemampuan penalaran matematis kelas pembelajaran biasa. Hasil ini relevan dengan penelitian yang dilakukan Huda, M. \& Arief, A. (2013, hlm. 34). Penelitian tersebut menunjukkan keterlaksanaan proses pembelajaran dengan menerapkan multiple intelligences menggunakan model pembelajaran Kooperatif Tipe Jigsaw di kelas eksperimen terlaksana dengan baik meskipun ada kendala pada pengelolaan waktu. Penerapan pembelajaran multiple intelligences menggunakan model pembelajaran Kooperatif Tipe Jigsaw di kelas eksperimen mendapat respons yang baik dari siswa.

Diterimanya hipotesis penelitian yang pertama tidak terlepas dari strategi pembelajaran multiple intelligeces yang diterapkan di kelas eksperimen.
Sebagaimana dikemukakan Yalmanci \& Gözüm (2013, hlm. 33) bahwa, "the education based on the theory of multiple intelligences affect the permanence of information more positively than traditional methods of teaching". Keduanya mempercayai yang berdasarkan hasil penelitian bahwa pendidikan berdasarkan teori multiple intelligences mempengaruhi kelanggengan informasi lebih positif pada siswa daripada metode pembelajaran biasa.

Dilihat dari proses pembelajaran di kelas eksperimen, secara umum siswa terlibat aktif dalam pembelajaran. Baik itu dalam proses berpikir, berdiskusi maupun memaparkan kembali. Indikator bahwa siswa terlibat aktif dalam aktivitas berpikir tergambar dalam respon yang diberikan melalui lisan maupun tulisan. Siswa juga melakukan aktivitas tidak hanya individu tapi juga kelompok dengan berdiskusi memecahkan permasalahan yang disodorkan dalam lembar kerja siswa serta lewat interaksi kelas dengan guru maupun siswa lainnya yang mendorong kinerja siswa lebih konstruktif.

Meskipun begitu, pencapaian peningkatan kemampuan penalaran siswa belum begitu memuaskan. Rata-rata perolehan skor postes siswa kelas eksperimen hanya 16,88 dari skor maksimum 36. Meningkat dari rata-rata perolehan skor pretes siswa kelas eksperimen yang hanya mencapai 8,05. Dilihat dari peningkatannya yang diukur dengan gain ternormalisasi siswa kelas eksperimen hanya mencapai tingkat sedang.

Hal ini jelas menunjukkan ada yang tidak berjalan dengan baik meskipun secara proses pembelajaran sudah dilakukan sesuai dengan petunjuk tentang strategi multiple intelligences itu sendiri. Padahal menurut pandangan konstruktivisme tentang belajar bahwa ketika individu dihadapkan dengan informasi baru, ia akan menggunakan pengetahuan siap dan pengalaman pribadi yang telah dimilikinya untuk membantu memahami materi baru tersebut (Herman, 2007, hlm. 53). 
Namun memang, kenyataan bahwa strategi multiple intelligences merupakan strategi yang sangat disukai di bidang pendidikan anak-anak. Strategi ini seperti pintu yang dibuka untuk membedakan desain umum dari isi pembelajaran, penggunaan kegiatan pembelajaran, komunikasi dan wacana antara pelajar dan guru, dan meningkatkan interaksi siswa (Osciak \& Milheim dalam Calik, \& Birgii, 2013, hlm. 9).

Karena kenyataan bahwa teori multiple intelligences fokus pada siswa aktif dan beberapa cara untuk belajar berdasarkan gaya belajar yang individu, dapat memegang sendiri dalam adegan sejarah ilmu pendidikan. Tentu saja tidak setiap teori seperti tabu, di mana-mana orang dan perubahan yang ada sehingga baik kritik dan pujian dikenakan muncul. Sak (dalam Calik, \& Birgii, 2013, hlm. 9) juga menyoroti bahwa salah satu kesalahan diyakini adalah untuk melihat teori multiple intelligences sebagai kebenaran mutlak bukan teori nominatif. Karena pada dasarnya multiple intelligences masih sebatas teori yang bisa terbukti berhasil, sebaliknya bisa juga tidak.

\section{Self Esteem}

Lebih parah lagi pada peningkatan self esteem siswa. Meskipun secara umum siswa baik di kelas eksperimen maupun di kelas kontrol tidak menunjukkan self esteem yang rendah terhadap pembelajaran matematika, namun tidak terdapat perbedaan yang signifikan pada peningkatan self esteem siswa di kedua kelas.

Tidak mudah memang meningkatkan self esteem hanya dalam delapan pertemuan karena berkaitan dengan sikap. Meningkatkan hal yang berkaitan dengan sikap itu lebih sulit karena memerlukan pembiasaan dalam jangka waktu yang cukup panjang. Agar peningkatan self esteem lebih tinggi, maka strategi multiple intelligences ini diharapkan bisa diterapkan di ruang-ruang kelas yang lebih banyak lagi.

Pada penelitian terdahulu, Engko (2008, hlm. 11) menguji enam hipotesis untuk melihat bagaimana pengaruh kepuasan kerja terhadap kinerja individual dengan self esteem dan self efficacy sebagai varaibel pemediasi. Dari hasil pengujian enam hipotesis, ada dua hipotesis yang tidak terdukung yaitu hipotesis satu yang mengukur hubungan antara kepuasan kerja dan self esteem. Hipotesis yang tidak terdukung juga pada hipotesis lima yang mengukur hubungan antara self esteem dan kinerja individual. Hasilnya menunjukkan bahwa self esteem memiliki hubungan negatif dengan kinerja individual. Keterbatasan penelitian Engko adalah sampel yang dipakai masih kurang representatif dengan sampel yang diambil hanya mahasiswa S2 UGM jurusan ilmuilmu sosial yang berprofesi sebagai dosen. Penelitian mendatang diharapkan dapat menggunakan jumlah sampel yang lebih besar agar hasil yang diperoleh dapat mewakili populasi. Penelitian selanjutnya juga dapat menggunakan variabel personalitas lainnya yang dapat menunjukkan pengaruh kepuasan kerja terhadap kinerja individual.

Temuan Kröner-Herwig, dkk. (2014, hlm. 2) menunjukkan bahwa sebuah keluarga dengan iklim negatif secara signifikan diprediksi akan membuat self esteem yang rendah. Sebab self esteem sebagiannya ditentukan oleh variabel dari lingkungan keluarga. Integrasi keluarga miskin dan dukungan keluarga rendah diprediksi akan membuat self esteem anakanak rendah, sedangkan kelekatan akan menunjukkan hubungan positif. Dan yang harus diperhatikan adalah temuan Bleidorn, et al. (2015, hlm. 13) bahwa pria cenderung memiliki self esteem lebih tinggi daripada wanita, dan kedua jenis kelamin menunjukkan peningkatan usia dinilai dalam diri dari masa remaja akhir hingga dewasa tengah.

Selain di rumah, sekolah pun sangat memiliki andil dalam meningkatkan self esteem siswa. Agar mencapai tingkat yang diinginkan, Ho (2003, hlm. 82) merekomendasikan di sekolah agar menyediakan pre-service dan in-service 
training bagi guru, administrator, dan orang tua pendidik pada keterampilan dan pengetahuan bekerja dengan orang tua tentang cara untuk memberikan dukung-an belajar di rumah dan di sekolah. Hal ini bisa membantu siswa menumbuhkan self esteem yang tinggi.

Di samping temuan kekurangan yang telah dikemukakan di atas, kompetensi pedagogik yang dimiliki peneliti belum semumpuni guru ideal. Sebagaimana disampaikan guru observer dalam catatan lapangannya. Bahwa peneliti baru sebatas menjalankan peran sebagai pengajar, belum menjadi seorang pendidik. Gestur tubuh, mimik muka yang tampak pada peneliti di hadapan siswa tidak seperti guru yang seharusnya.

Sosok guru ideal yang dimaksud adalah guru yang mewujud sosok yang digugu dan ditiru, bukan digugu meskipun keliru. Menurut Ward (Maulana, 2014, 8), "The mediocre teacher tells. The good teacher explains. The superior teacher demonstrates. The great teacher inspires". Guru yang biasa saja pandai bercerita. Guru yang baik adalah mereka yang pandai memberikan penjelasan. Guru yang unggul adalah guru yang dapat mendemonstrasikan kemampuannya.

Sementara itu, guru Besar UPI, H. M. Surya (dalam Zaenuddin, 2013, hlm. 214-215) mengemukakan, terdapat empat level guru yang dikenal di dunia pendidikan. Tiap level memiliki kapasitas dan kualitas yang berbeda-beda. Pertama, guru aktual yakni guru yang datang ke sekolah, ikut PLPG, terima sertifikasi mengajar, tapi batinnya belum tentu menjadi guru. Kedua, guru harmonis yakni guru yang biasa, bisa mengajar dengan baik, tekun, rajin, bagus, tapi batinnya tidak bermula ingin jadi guru. Ketiga, guru karakter yakni guru yang tampil penuh dengan karakternya. Keempat, guru qolbu yakni guru yang benar-benar jadi puncak, guru dengan level tertinggi. Yakni guru yang penampilannya berbasis kualitas qolbu atau hatinya secara tulus ikhlas.
Pada akhirnya, berkaca pada pendapat Chau (2006, hlm. 13) bahwa gaya belajar dan teori multiple intelligences bukan satu-satunya pendekatan yang efektif untuk menangani sifat kompleks dari pembelajaran manusia; masih ada teori lain yang sama pentingnya. Sejalan dengan pendapat Nisbet yang menyatakan bahwa tidak ada cara mengajar yang paling benar sebagaimana tidak ada pula cara belajar yang paling baik (Suherman, dkk. dalam Maulana, 2010, hlm. 32).

\section{KESIMPULAN}

Berdasarkan hasil penelitian yang dipaparkan pada bagian sebelumnya, diperoleh beberapa kesimpulan sebagai berikut ini.

1. Peningkatan kemampuan penalaran matematis siswa yang memperoleh pembelajaran dengan strategi multiple intelligences lebih baik secara signifikan daripada rank peningkatan kemampuan penalaran matematis kelas pembelajaran biasa.

2. peningkatan self esteem siswa yang memperoleh pembelajaran dengan strategi multiple intelligences tidak lebih baik secara signifikan daripada rank hasil postes self esteem kelas pembelajaran biasa.

Berdasarkan temuan dalam penelitian ini, maka peneliti mengajukan beberapa rekomendasi sebagai berikut ini.

1. Penelitian ini dilakukan dalam lingkup populasi terbatas. Untuk itu, agar hasil penelitian ini dapat digeneralisasikan, perlu diadakan penelitian lain pada populasi yang berbeda, jenjang pendidikan yang berbeda maupun pada topik yang berbeda.

2. Bagi peneliti selanjutnya yang berminat mengungkap penerapan strategi multiple intelligences, hendaknya dapat digunakan untuk mengukur ranah afektif matematika lainnya yang lebih luas seperti self regulated learning atau kompetensi matematika lainnya yang 
memiliki keterkaitan secara konseptual dengan strategi multiple intelligences.

\section{DAFTAR PUSTAKA}

Baccus, J. R., Baldwin, M. W. \& Packer, D. J. (2004). Increasing Implicit SelfEsteem Through Classical Conditioning. American Psychological Society. 15 (7). Hlm. $498-502$.

Bleidorn, W. et al. (2015). Age and Gender Differences in Self-Esteem - A Cross Cultural Window. Journal of Personality and Social Psychology. Hlm. 1 - 15.

Calik, B. \& Birgii, B. (2013). Multiple Intelligence Theory for Gifted Education: Criticisms and Implications. Journal for the Education of the Young Scientist and Giftedness. 1 (2). Hlm. 1-12.

Chau, M. Y. (2006). Connecting Learning Styles and Multiple Intelligences Theories Through Learning Strategies: An Online Tutorial for Library Instruction. Academic Journal. 16 (1). Hlm. 5 - 18.

DePorter, B., Reardon, M., dan Nourie, S. S. (2005). Quantum Teaching: Mempraktikkan Quantum Learning di Ruang-ruang Kelas. Bandung: Kaifa.

Eberle, S. G. (2011). Playing with the Multiple Intelligences: How Play Helps Them Grow. American Journal of Play. 4 (1). Hlm. 19-51.

Engko, C. (2008). Pengaruh Kepuasan Kerja terhadap Kinerja Individual dengan Self Esteem dan Self Efficacy sebagai Variabel Intervening. Jurnal Bisnis dan Akuntansi. 10 (1). Hlm. 1 $-12$.

Erol, R. Y. \& Orth, U. (2011). Self-Esteem Development From Age 14 to 30 Years: A Longitudinal Study. Journal of Personality and Social Psychology. 101 (3). Hlm. 607 619.
Gardner, H. (2013). Kecerdasan Majemuk: Teori dalam Praktik. Tangerang Selatan: Interaksara.

Herman, T. (2006). Pembelajaran berbasis masalah untuk meningkatkan kemampuan penalaran matematis siswa smp. Diakses dari: http://upi.edu/directoryfiles/Tatang. pdf.

Herman, T. (2007). Pembelajaran berbasis masalah untuk meningkatkan kemampuan berpikir matematis tingkat tinggi siswa sekolah menengah pertama. Educasionist. 1 (1). Hlm. 47 - 56 .

Ho, E. S. (2003). Students' Self-Esteem in an Asian Educational System: Contribution of Parental Involvement and Parental Investment. School Community Journal. 13 (1). Hlm. $65-84$.

Huda, M. \& Arief, A. (2013). Pengaruh Multiple Intelligences Menggunakan Model Pembelajaran Kooperatif Tipe Jigsaw Terhadap Hasil Belajar Siswa Pada Pokok Bahasan Listrik Dinamis Kelas X Di SMAN 1 Porong. Jurnal Inovasi Pendidikan Fisika. 2 (3). Hlm. 34 37.

Kröner-Herwig, B., Maas, J. \& Reckling, P. (2014). Self-Esteem in a German Population Sample of Children and Adolescents: Association with Demographic and Psychosocial Variables. Journal of Child \& Adolescent. 12. Hlm. 1 - 10.

Lunenburg, F. C. \& Lunenburg, M. R. (2014). Applying Multiple Intelligences in the Classroom: A Fresh Look at Teaching Writing. International Journal of Scholarly Academic Intellectual Diversity. 16 (1). Hlm. 1-14.

Lutan, R. (2003). Self Esteem: Landasan Kepribadian. Jakarta: Bagian Proyek Peningkatan Mutu Organisasi dan Tenaga 
Keolahragaan Dirjen Olahraga Depdiknas.

Maulana (2014). Menakar Profesionalisme Guru, Antara Tataran Idealis dan Praktis. Makalah disajikan pada Seminar Nasional tentang Profesionalisme Guru yang diselenggarakan oleh Jurusan Pendidikan Bahasa dan Sastra Indonesia STKIP Sebelas April Sumedang, tanggal 15 November 2014.

Muharom, T. (2014). Pengaruh Pembelajaran Dengan Model Kooperatif Tipe Student Teams Achievement Division (STAD) Terhadap Kemampuan Penalaran Dan Komunikasi Matematik Peserta Didik Di SMK Negeri Manonjaya Kabupaten Tasikmalaya. Jurnal Pendidikan dan Keguruan. 1 (1). Hlm. 1 - 11.

Putrawan, G. D., Rukayah, dan Hadiyah (2011). Keefektifan Strategi Multiple Intelligences pada Pembelajaran IPS di Sekolah Dasar. PGSD FKIP Universitas Sebelas Maret Surakarta.

Srivastava, R. \& Joshi, S. (2014). Relationship Between Self-Concept and Self-Esteem in Adolescents.
International Journal of Advanced Research. 2 (2). Hlm. 36-43.

Tafti, M. A., Heidarzadeh, M., \& Khademi, M. (2014). A Comparison of Multiple Intelligences Profile of Students with and without Learning Disabilities. International Journal of Applied Psychology. 4 (3). Hlm. 121 $-125$.

Tajudin, N. M. \& Chinnappan, M. (2016). Relationship Between Scientific Reasoning Skills and Mathematics Achievement Among Malaysian Students. Geografia Online Malaysian Journal of Society and Space. 12 (1). Hlm. 96 - 107.

Yalmanci, S. G. \& Gözüm, A. I. C. (2013). The Effects of Multiple Intelligence Theory Based Teaching on Students' Achievement and Retention of Knowledge (Example of the Enzymes Subject). International Journal on New Trends in Education and Their Implications. 4 (3). Hlm. $27-36$.

Zaenuddin. (2013). Een sukaesih sang guru qolbu: terbaring lumpuh 30 tahun tapi terus mengajar dari tempat tidurnya. Jakarta Selatan: Change Publication. 